\title{
Increase of Escherichia coli Inoculum Doses Induces Faster Innate Immune Response in Primiparous Cows
}

\author{
F. Vangroenweghe, ${ }^{1}$ P. Rainard, ${ }^{2}$ M. Paape,${ }^{3}$ L. Duchateau, ${ }^{1}$ and C. Burvenich ${ }^{1}$ \\ ${ }^{1}$ Ghent University, Faculty of Veterinary Medicine, \\ Department of Physiology, Biochemistry, and Biometrics, \\ Salisburylaan 133, 9820 Merelbeke, Belgium \\ ${ }^{2}$ Institut National de Recherche Agronomique, \\ Laboratoire de Pathologie Infectieuse et Immunologie, \\ Centre de Tours-Nouzilly, 37380 Nouzilly, France \\ ${ }^{3}$ Bovine Functional Genomics Laboratory, USDA-ARS, \\ Beltsville, MD 20705
}

\begin{abstract}
The objective of the current study was to evaluate the dynamics of infection and the immunological response to varying numbers of Escherichia coli injected into the mammary glands of primiparous cows during the periparturient period. Primiparous cows have been shown to be more resistant to intramammary $E$. coli challenge, and an increase of the inoculum dose by 2 $\log _{10}$ units induced a more rapid clinical response and clearance of the organisms. Recognition of lipopolysaccharide (LPS) is a key event in the innate immunity response to gram-negative infection and is mediated by the accessory molecules CD14 and LPS-binding protein (LBP). Primiparous cows were inoculated with $1 \times 10^{4}$ (Group A; n = 8) or $1 \times 10^{6}$ (Group B; n = 8) cfu E. coli $\mathrm{P} 4$ :O32 in their 2 left quarters during the periparturient period. Clinical examination and analysis of blood and milk parameters, including IL-8, complement fragment 5a (C5a), LBP, and soluble CD14 (sCD14), were performed from $d-4$ to $d+3$ relative to infection. Primiparous cows in Group B initiated a more rapid clinical response following intramammary infection (IMI), resulting in typical clinical signs and changes in blood and milk parameters approximately $3 \mathrm{~h}$ earlier compared with primiparous cows in Group A. Based on average milk production in the noninfected quarters on $\mathrm{d}+2$ postinoculation, all heifers reacted as moderate responders. Distinct differences in the kinetic patterns of rectal temperature, somatic cell count (SCC), IL-8, C5a, LBP, and sCD14 were observed between both groups during the early phase of inflammation. Both C5a and IL-8 increased before cellular influx into the infected glands, followed by increases in sCD14 and
\end{abstract}

Received February 9, 2004.

Accepted June 21, 2004.

Corresponding author: C. Burvenich; e-mail: christian.burvenich @UGent.be.
LBP. In conclusion, primiparous cows are able to clear an intramammary $E$. coli infection efficiently. Moreover, increasing the inoculum dose induces a more rapid inflammatory reaction, mainly because of early activation of the innate host immune response.

(Key words: primiparous dairy cow, Escherichia coli, mastitis, inoculum size)

Abbreviation key: BLC = blood leukocyte count, C5a $=$ complement fragment 5a, LBP $=$ LPS-binding protein, $\mathbf{m C D 1 4}=$ membrane-associated CD14, PIH = postinfusion hour, PMN = polymorphonuclear neutrophil, sCD14 = soluble CD14, TLR = Toll-like receptor, QMP = quarter milk production .

\section{INTRODUCTION}

The importance of innate immunity in recognizing microbial pathogens and mounting a response against them is now widely recognized. The immediate, innate immune response is mediated largely by white blood cells, such as polymorphonuclear neutrophils (PMN) and macrophages, cells that phagocytose and kill the pathogens and concurrently coordinate additional host responses by synthesizing a wide range of inflammatory mediators and cytokines (Aderem and Ulevitch, 2000). Several species of gram-negative bacteria, including Escherichia coli, Klebsiella pneumoniae, and various species of Enterobacter, are common mastitis pathogens and are all characterized by the presence of endotoxin or LPS in their outer membrane. Lipopolysaccharide is a proinflammatory molecule that is shed from the bacterial surface during bacterial replication or death (Burvenich et al., 2003). Clinical signs following experimentally induced $E$. coli mastitis contributed to mediator shock, rather than to endotoxin shock, because endotoxin mainly plays a local role (Hoeben et al., 2000; Dosogne et al., 2002).

Several of the proinflammatory cytokines that mediate the localized and systemic response to gram-nega- 
tive mastitis, including IL-1 $\beta$, IL-6, IL- 8 , and TNF- $\alpha$, are up-regulated by LPS (Shuster et al., 1993; Guha and Mackman, 2001). The up-regulation of these cytokines is mediated by the interaction of LPS with the accessory proteins, LPS-binding protein (LBP), and CD14 (Guha and Mackman, 2001). An acute phase protein binding with circulating LPS, LBP, facilitates the transfer of LPS to membrane-associated CD14 (mCD14), which is found on PMN and cells of the monocytic lineage (Wright et al., 1990). The mCD14 is a glycosyl phosphatidylinositol-anchored protein that lacks an intracellular cytoplasmic domain, rendering it incapable of signal transduction across the cell membrane. In cells lacking mCD14, such as epithelial and endothelial cells, activation is dependent on cellular recognition of LPS-LBP complexes bound to circulating soluble CD14 (sCD14), which is derived from the shedding of mCD14 (Tapping and Tobias, 1997) from CD14bearing cells. Toll-like receptor (TLR)-4 has been identified in both cells of the monocytic lineage and nonmCD14-bearing cells as a LPS transmembrane receptor capable of activating cells (Chow et al., 1999; Faure et al., 2000). Recently, it was shown that LBP, in addition to transferring LPS to CD14, also forms an integral part of a trimolecular LPS-LBP-sCD14 complex. Monocytes can, therefore, detect the presence of LPS at concentrations as low as $10 \mathrm{pg} / \mathrm{mL}$ (Thomas et al., 2002). Transmembrane signaling and cell activation in cells lacking mCD14 are thought to be associated with TLR-4 through a cell surface assembly of a multiprotein recognition complex consisting of CD14, MD-2, and TLR-4 (Akashi et al., 2000). Activation and transmembrane signal transduction through the TLR-4 complex activates several NF- $\kappa \mathrm{B}$ controlled genes such as IL-8 in endothelial cells (Aderem and Ulevitch, 2000).

A role for sCD14 and LBP in mediating bovine host responses to intramammary LPS or $E$. coli challenge has recently been demonstrated (Wang et al., 2002; Bannerman et al., 2003; Lee et al., 2003a, b). Following intramammary LPS infusion, sCD14 increases in milk (Bannerman et al., 2003; Lee et al., 2003a) paralleled by an increase in LBP (Bannerman et al., 2003). Moreover, sCD14 has been shown to sensitize the mammary gland to LPS (Wang et al., 2002) and to reduce the severity of experimental $E$. coli mastitis in mice (Lee et al., 2003c) and cows (Lee et al., 2003b). Interestingly, maximal levels of the chemoattractant IL-8 were observed before increases in either milk LBP or sCD14. This suggests that initial host cell activation can occur in the presence of basal levels of sCD14 and LBP (Bannerman et al., 2003). Furthermore, PMN influx, as determined by SCC, were similarly elevated before increases in sCD14 and LBP, indicating that heightened levels of these molecules were not required for immediate host innate immune responses (Bannerman et al., 2003).

Several physiological factors impact the clinical outcome of E. coli mastitis (Burvenich et al., 2003). Early lactating cows, infected with $E$. coli, are more severely affected than cows after peak lactation (Hill, 1981). This is mainly due to the impairment of early lactation leukocyte function, which begins a few weeks before parturition and only recovers several weeks postpartum (Kehrli et al., 1989; Sordillo and Babiuk, 1991a, b; Sordillo and Peel, 1992; Detilleux et al., 1995; Dosogne et al., 1999; Mehrzad et al., 2002). This pronounced immunosuppresion is not only related to parturition itself (Kimura et al., 1999), but it is influenced by several periparturient diseases (Kehrli and Goff, 1989) and has a consequence on many other diseases, such as retained placenta (Kimura et al., 2002). In addition to stage of lactation, parity was also reported to be an important physiological factor that influences severity of clinical mastitis (Gilbert et al., 1993; van Werven et al., 1997; Mehrzad et al., 2002; Vangroenweghe et al., 2004). Blood PMN function was higher in younger animals than in cows after their fourth parturition (Gilbert et al., 1993; van Werven et al., 1997). Moreover, PMN viability and oxidative burst activity have been found to be significantly different between primiparous cows and multiparous cows during the periparturient period (Mehrzad et al., 2002). In a nonrandomized intramammary challenge study using large numbers of $E$. coli, primiparous cows reacted as moderate responders based on their quarter milk production (QMP) in the noninfected quarter on $d+2$ postinfection. Based on clinical severity, all of the primiparous animals were scored as mild to moderate in their clinical response throughout the entire experimental challenge period (Vangroenweghe et al., 2004).

The purpose of the present study was to quantify several inflammatory mediators and cytokines and to evaluate the outcome of intramammary $E$. coli inoculation in primiparous cows under identical conditions as described previously (Vangroenweghe et al., 2004) with a fully randomized study design, using 2 high inoculum doses, with a 100 -fold difference $\left(1 \times 10^{4}\right.$ and $\left.1 \times 10^{6}\right)$ in colony-forming units. This difference in inoculum dose was based on the amount of LPS produced related to the number of $E$. coli bacteria injected (Burvenich, 1983; Monfardini et al., 1999). The hypothesis of the present study is that the application of 2 different inoculum doses elicits differences of the innate immune response. An effect of 2 different inoculum doses in highly resistant primiparous cows has never been studied before, and it is important to have a better insight into the mechanism of innate immune response in these animals. 


\section{MATERIALS AND METHODS}

\section{Experimental Animals and Study Facilities}

All primiparous cows $(\mathrm{n}=16)$ calved within $3 \mathrm{~d}$ before arrival at the dairy facility (Commercial Dairy Farm Oudenaarde, Oudenaarde, Belgium). They were fed twice daily at 0700 and $1700 \mathrm{~h}$. The ration consisted of corn silage, good quality hay, and water for ad libitum intake. Concentrates (Sandilac; Dumoulin Voeders Sanders, Moorslede, Belgium) were fed according to milk production.

For inclusion into the trial, treatment of clinical diseases was not allowed within $10 \mathrm{~d}$ before intramammary inoculation. Animals were free of major mastitis pathogens through 3 consecutive bacteriological examinations and with a quarter foremilk SCC $<200,000$ cells/ $\mathrm{mL}$. Primiparous cows accepted for the intramammary challenge were inoculated between 14 and $28 \mathrm{~d}$ postparturition.

Milking was performed daily at 0800 and $1800 \mathrm{~h}$ using a quarter milking machine (Packo \& Fullwood, Zedelgem, Belgium). The QMP was measured at d -4 , $-1,0$ (postinfusion hour [PIH] 0 to 24), 1 (PIH 24 to 48), 2 (PIH 48 to 72 ), and 3 (PIH 72 to 96 ).

\section{Inoculation Dose}

The generation time of $E$. coli in mammary secretions can be as short as 20 min (Burvenich et al., 2003). Because we were interested in bacterial elimination rather than in bacterial growth in experimentally infected mammary glands, 2 high inoculum doses, $1 \times 10^{4}$ (Group A; $\mathrm{n}=8$ ) and $1 \times 10^{6}$ (Group B; $\mathrm{n}=8$ ) cfu, were used.

\section{Intramammary Inoculation Procedure}

Inoculation was performed as previously described (Vangroenweghe et al., 2004). Briefly, E. coli P4:O32 (Bramley, 1976) (H37, $\beta$-glucuronidase + , haemolysin $-)$, maintained in lyophilization medium at $-20^{\circ} \mathrm{C}$, was subcultured in brain-heart infusion broth (CM225; Oxoid, Nepean, ON, Canada) at $37^{\circ} \mathrm{C}$ during 3 consecutive $\mathrm{d}$, subsequently washed $3 \times$ with pyrogen-free PBS, and resuspended in PBS. Just before inoculation, the suspension was diluted in pyrogen-free PBS to a final concentration of $1 \times 10^{4} \mathrm{cfu} / \mathrm{mL}$ (Group A) or $1 \times 10^{6} \mathrm{cfu} /$ $\mathrm{mL}$ (Group B). On d 0, 30 min after morning milking (1.5 $\mathrm{h}$ after feeding), the cows were inoculated in the left front and rear quarters with a total volume of 10 $\mathrm{mL}$, consisting of $1 \mathrm{~mL}$ of inoculum and $9 \mathrm{~mL}$ of pyrogenfree saline solution $(\mathrm{NaCl}$ 0.9\%; Baxter N.V., Lessines, Belgium) per quarter.
Animals were randomly assigned to one of both treatment groups and challenged on 2 different trial $\mathrm{d}$ (8 cows per challenge day, 4 cows per treatment group).

\section{Sampling Procedure}

Blood and milk samples were collected at $\mathrm{d}-4,-1$, $0,1,2$, and 3 relative to the day of challenge. On the day of challenge, blood and milk samples were collected at PIH 3, 6, 9, 12, 15, 18, and 21.

Blood samples were drawn $(10 \mathrm{~mL})$ aseptically from the external jugular vein of each cow by venipuncture into evacuated tubes for preparation of plasma and serum. Foremilk was aseptically collected for diagnostic bacteriology, SCC, and preparation of skimmed milk. All samples were maintained on ice up to the time of processing.

\section{Clinical Examination}

Rectal temperature, heart rate, respiration rate, rumen motility, skin turgor, fecal appearance, appetite, general attitude, BCS (Edmondson et al., 1989), and aspects of the mammary gland (abnormal milk, swelling, teat relaxation, and milk leakage) (Massart-Leën et al., 1988) were recorded by a veterinarian each time blood and milk samples were collected.

\section{Severity Determination}

The severity of $E$. coli mastitis was determined based on QMP in the noninfected quarters at d 2 postinfusion. Animals with a QMP in the noninfected quarters at d +2 that was $>50 \%$ compared with their QMP at $d-1$ in the same quarters were scored as moderate responders, whereas animals with a QMP at $d+2$ that was $<50 \%$ were considered severe responders (Vandeputte-Van Messom et al., 1993; Dosogne et al., 1997, 1999; Vangroenweghe et al., 2004). Clinical severity estimation was scored as described by Vangroenweghe et al. (2004). Briefly, clinical data (rectal temperature, skin turgor, reticulorumen motility, and general attitude) obtained from PIH 9 to 48 were scored as described in Table 1, and based on their total score, primiparous cows were classified into mild, moderate, and severe responders.

\section{SCC and Milk Composition}

Somatic cell count was determined using a fluoroopto electronic method (Fossomatic 400 cell counter; Foss Electrics, Hillerød, Denmark). Lactose concentration $(\mathrm{g} / \mathrm{L})$ was determined using midinfrared photospectrometry (Foss Electrics). 
Table 1. Severity estimation scheme, based on systemic disease signs for the classification of heifers, following an experimental inoculation with Escherichia coli P4:O32 (Vangroenweghe et al., 2004). Briefly, the 4 parameters are scored. Then, the total score is calculated and compared with respective ranges for classification into mild, moderate, or severe disease.

\begin{tabular}{lll}
\hline Variable & Criteria & Score \\
\hline Rectal temperature $\left({ }^{\circ} \mathrm{C}\right)$ & 37.80 to 39.25 & 0 \\
& 39.30 to 39.80 & 1 \\
Skin turgor & $>39.80$ or $<37.80$ & 2 \\
& Regains normal shape in $<5 \mathrm{~s}$ & 0 \\
Rumen motility rate (contractions/min) & $>5$ s to regain normal shape & 1 \\
& $3 \times / 2$ min & 0 \\
General attitude (signs of depression) & 1 to $2 \times / 2$ min & 1 \\
& $0 \times / 2$ min & 2 \\
& Alert & 0 \\
Total score & Lethargic & 1 \\
& Depressed-unable to stand & 2 \\
& Extremely sick一recumbent & 3 \\
\hline
\end{tabular}

\section{Indicators of the Breakdown of the Blood-Milk Barrier}

Milk samples for the determination of sodium, chlorine, and potassium concentrations $(\mathrm{m} M / \mathrm{L})$ were centrifuged at $1000 \times \mathrm{g}\left(30 \mathrm{~min}, 4^{\circ} \mathrm{C}\right)$. Fat was removed, and samples of skim milk were taken and immediately frozen at $-80^{\circ} \mathrm{C}$ until analysis. After thawing, ion concentration was analyzed using an ion-selective electrode analyzer (Ilyte; Instrumentation Laboratories, Milan, Italy).

\section{Blood Leukocyte Count and Differentiation}

Blood leukocyte count (BLC) $\left(\log _{10} / \mathrm{mL}\right)$ was determined using an electronic particle counter (Coulter Counter Z2; Coulter Electronics Ltd., Luton, UK). Differential BLC was performed on blood smears. Briefly, $10 \mu \mathrm{L}$ of mixed whole blood were added onto a microscope slide, and very thin smears were prepared. Following drying, smears were stained as described previously (Mehrzad et al., 2001). Differential counts of the blood smears were carried out according to Wilde (1964). Two hundred cells were counted on each smear, and the percentage of PMN (mature, band cells and myelocytes-metamyelocytes), monocytes, lymphocytes, and eosinophils was determined. Myelocytes-metamyelocytes were characterized by their round-oval to elongated-arciform nuclei with yellowish cytoplasm. Band cells had longer, circular formed nuclei with more condensed chromatin, situated near the periphery of the cell. Mature PMN had clearly defined nuclei with 3 to 6 lobes and typical neutral granules. Monocytes were round to irregular in shape containing greyish-blue cytoplasm, with foamy appearance in which fine red gran- ules can be found. The nuclear substance has a fine reticulate structure with evenly distributed chromatin. Lymphocytes had compact nuclei, surrounded by cytoplasm varying from a narrow band to a wider, more irregular mass. Eosinophils had their specific eosinophilic granules in the cytoplasm and nuclei with 2 to 3 lobes.

\section{Colony-Forming Units in the Inoculated Quarters}

The number of $E$. coli (cfu/mL) after experimental inoculation was determined by appropriate 10 -fold dilutions of each milk sample in PBS. Ten microliters of these dilutions were plated out on Columbia Sheep Blood agar (Biokar Diagnostics, Beauvois, France). All dilutions were performed in duplicate. Colonies were counted after a $24-\mathrm{h}$ incubation at $37^{\circ} \mathrm{C}$. The colony count was converted to $\mathrm{cfu} / \mathrm{mL}$ based on the factor of dilution and finally expressed as $\log _{10} / \mathrm{mL}$ for statistical analysis.

\section{ELISA for IL-8}

Milk IL-8 levels were determined from undiluted whey samples assayed with a commercially available human IL-8 ELISA kit (R\&D Systems, Inc., Minneapolis, MN). The antibody pairs used in this kit have been previously shown to cross-react with bovine IL-8 (Shuster et al., 1996, 1997). The optical density at $450 \mathrm{~nm}$ and a correction wavelength of $550 \mathrm{~nm}$ were measured on an automated microplate reader (Bio-Kinetics Reader; Bio-Tek Instruments, Winooski, VT). Values expressed in picograms per milliliter were extrapolated using linear regression from a standard curve of known amounts of human IL-8. 


\section{ELISA for Complement Fragment 5a}

Using ELISA, the complement fragment 5a (C5a) was quantified as previously described (Rainard et al., 1998). Briefly, flat-bottomed microtiter plates (Immulon 1; Dynatech, Chantilly, VA) were coated with 100 $\mu \mathrm{L}$ of goat antimouse IgG (Jackson Immunoresearch Laboratories, West Grove, PA) diluted to $2 \mu \mathrm{g} / \mathrm{mL}$ in $0.1 M$ carbonate bicarbonate buffer $(\mathrm{pH} \mathrm{9.6)}$ for $1.5 \mathrm{~h}$ at $39^{\circ} \mathrm{C}$. After each incubation, the plates were washed $5 \times$ with PBS supplemented with $0.1 \%$ (vol/vol) Tween 20. Unsaturated binding sites were blocked with a solution of $0.5 \%(\mathrm{wt} / \mathrm{vol})$ gelatin. The sequence of incubation steps with $100-\mu \mathrm{L}$ reagents diluted with PBS supplemented with $0.1 \%$ (vol/vol) Tween 20 plus $0.1 \%$ gelatin was as follows: 1) a 1/10,000 dilution of the antiC5a Mab 6G4 for $1 \mathrm{~h}$; 2) 2-fold dilutions of purified C5a $\mathrm{a}^{\text {desArg }}$ for the calibration curve, or appropriate dilutions of the sample under test, diluted in PBS supplemented with $0.1 \%$ (vol/vol) Tween 20 plus $0.1 \%$ gelatin containing $1 \mathrm{~m} M$ EDTA for $1.5 \mathrm{~h}$; 3) a 1/5000 dilution of rabbit antibovine $\mathrm{C} 5 \mathrm{a} / \mathrm{C} 5$ for $30 \mathrm{~min}$; 4) a 1/10,000 dilution of goat antirabbit IgG (Jackson Immunoresearch Laboratories) for $30 \mathrm{~min}$; 5) $52 \mathrm{mM}$ 2,2'-azido-di-(3-ethylbenzthiazoline-6-sulfonic acid) (ABTS; Sigma) in $0.1 \mathrm{M}$ citrate buffer ( $\mathrm{pH} 4.2$ ) with $7.5 \mathrm{~m} M$ hydrogen peroxide (Sigma). The absorbance at $415 \mathrm{~nm}$ was read after about 30 min with an automated microplate reader (Bio-Kinetics Reader; Bio-Tek Instruments). Values expressed in nanograms per milliliter were extrapolated using linear regression from a standard curve of known amounts of C5a ${ }^{\text {desArg }}$ (Rainard et al., 1998).

\section{ELISA for sCD14}

A sandwich ELISA was used to quantify sCD14 levels in milk as described by Bannerman et al. (2003). Briefly, flat-bottom 96-well plates were coated overnight with 5 $\mu \mathrm{g} / \mathrm{mL}$ of mouse antibovine CD14 monoclonal antibody (CAM36A; VMRD, Inc., Pullman, WA) diluted in 0.05 $M$ sodium carbonate-bicarbonate (Sigma) $(\mathrm{pH} \mathrm{9.6)} \mathrm{at}$ $4^{\circ} \mathrm{C}$. The plates were washed $4 \times$ with $0.05 \%$ Tween 20 diluted in $50 \mathrm{mM}$ Trizma-buffered saline (Sigma) $(\mathrm{pH}$ 8.0) and subsequently blocked with $2 \%$ fish skin gelatin (Sigma Chemical Co.) for $1 \mathrm{~h}$ at room temperature. Plates were washed, and $100 \mu \mathrm{L}$ of diluted whey samples (1:10) were added to each well in duplicate. Plates were incubated for $1 \mathrm{~h}$ at room temperature and subsequently washed as previously described. Mouse antibovine CD14 antibody (MM61A; VMRD, Inc.) was conjugated to horseradish peroxidase using a commercially available kit (EZ-Link Plus Activated Peroxidase Kit; Pierce Chemical Co., Rockford, IL) and was used as the detection antibody. This horseradish peroxidaseconjugated antibovine CD14 antibody was diluted
1:1000 in Trizma-buffered saline wash buffer containing $2 \%$ gelatin, and $100 \mu \mathrm{L}$ of the resulting solution were added to each well. Plates were incubated for $1 \mathrm{~h}$ at room temperature and washed as previously described; $100 \mu \mathrm{L}$ of 3,3',5,5'-tetramethylbenzidine substrate solution (Pierce Chemical Co.) were added to each well. The reaction was stopped by the addition of $100 \mu \mathrm{L}$ of $2 M$ $\mathrm{H}_{2} \mathrm{SO}_{4}$, and the absorbance was read at $450 \mathrm{~nm}$ on a microplate reader (Multiskan PLUS; Labsystems, Helsinki, Finland). A background correction reading of 550 $\mathrm{nm}$ was subtracted from the 450-nm absorbance readings. Values expressed in micrograms per milliliter were extrapolated using linear regression from a standard curve of known amounts of recombinant bovine sCD14 (Wang et al., 2002).

\section{ELISA for LBP}

Milk and plasma LBP levels were determined with a commercially available LBP ELISA kit that crossreacts with bovine LBP (Cell Sciences, Inc., Norwood, MA). Milk and plasma samples were diluted 1:400 and 1:1500, respectively, and assayed according to the manufacturer's instructions. The optical density at $450 \mathrm{~nm}$ and a correction wavelength of $550 \mathrm{~nm}$ were measured on a microplate reader (Multiskan PLUS; Labsystems). The concentration of LBP was calculated by extrapolation using linear regression from a standard curve of known amounts of human LBP.

\section{Statistical Analysis}

To compare the 2 inoculum groups with respect to the various parameters analyzed in blood and milk, a mixed model was used, with cow as random effect and time, inoculum, and their interaction as categorical fixed effects. Furthermore, for the SCC, colony-forming units, rectal temperature, IL-8, C5a, sCD14, and LBP, the 2 inoculum doses were compared at PIH 6, 9, and 12 using Bonferroni's multiple comparisons procedure with an overall type I error equal to $5 \%$.

The significance between the number of animals in the different categories of the clinical score was tested using the Fisher Exact test.

\section{RESULTS}

\section{QMP Decreases Temporarily Because of the Intramammary E. coli Challenge}

In the infected quarters, QMP decreased $(P<0.0001)$ on $\mathrm{d} 0$, the day of intramammary inoculation. The maximal decrease of 60 to $70 \%$ appeared already on the day of infection (Figure 1a). The QMP decrease (68\%) was slightly more pronounced in Group B, with a slightly 
a

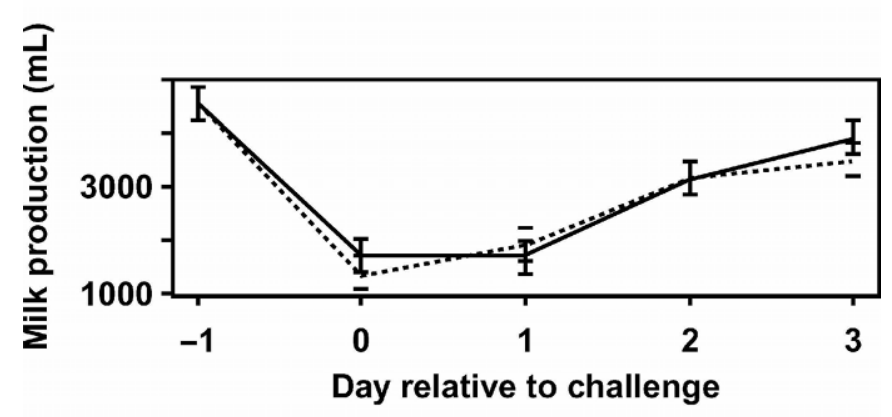

b

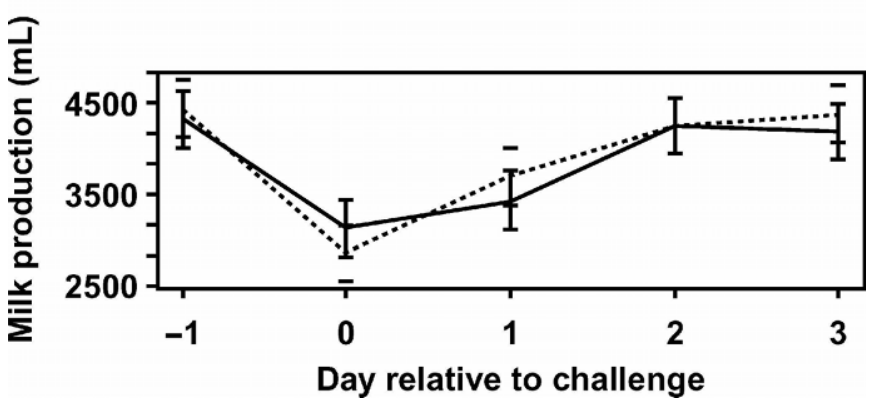

Figure 1. Milk production of the infected left (a) and noninfected right quarters (b) from $d-1$ until $d+3$ from primiparous cows infused with $1 \times 10^{4}\left(\right.$ - Group A; n = 8) and $1 \times 10^{6}(--$; Group B; $\mathrm{n}=8)$ cfu Escherichia coli P4:O32. Data are means ( \pm SEM).

more rapid recovery on $d+1$, but no significant differences between the 2 doses were found. On $d+3$, the recovery in the infected quarters was still incomplete and averaged 86 and $76 \%$ of the preinfection QMP in Groups A and B, respectively.

The QMP decrease in the contralateral noninfected quarters is considered to be an indicator of general systemic illness caused by IMI in the left quarters. A moderate and short-termed decrease in the QMP of the contralateral quarters was present in both infusion groups (Figure 1b). Based on QMP at $d+2$, no severe responders were observed in the 2 groups. At $d+3$, relative to the day of infusion, QMP of these quarters was at 97 and $99 \%$ of the preinfection QMP in Group $\mathrm{A}$ and $\mathrm{B}$, respectively.

\section{Intramammary Challenge with E. coli Induces Both a Local and Systemic Inflammatory Response}

After the intramammary $E$. coli inoculation in both infusion groups, rectal temperature rapidly increased and was significantly higher $(P<0.002)$ at PIH 6 and 9 in Group B compared with Group A. The fever peak appeared $3 \mathrm{~h}$ earlier and was highest in Group B, which received the $1 \times 10^{6} \mathrm{cfu}$ inoculum (Figure 2a). As indi- cated by the significant interaction between time and inoculum $(P<0.0001)$, the kinetics of the rectal temperature curve significantly differed between the infusion groups. Heart rate and respiration rate followed identical kinetics as rectal temperature (results not shown).

Rumen motility was reduced in both infusion groups from PIH 9 onward. However, the depression of reticulorumen motility was less pronounced in Group A, with only 3 animals showing a slight decrease in motility ( 1 to $2 \times / 2 \mathrm{~min}$ ); one animal showed a complete absence of reticulorumen activity at PIH 9. In Group $\mathrm{B}$, the depression of rumen motility was also maximal at PIH 9: 3 animals with absence of motility and 4 animals showing a slight decrease in rumen motility. Reticulorumen returned to normal motility by PIH 24 in both infusion groups (results not shown).

Local clinical signs at the level of the infected mammary glands appeared early during inflammation. In Group B, the first changes in milk appearance (color, flakes, etc.) occurred at PIH 9, with a maximum around PIH 15. Swelling of the infected quarters occurred at PIH 6, with a maximum on PIH 9, at the time when PMN influx in the glands became apparent through increases in SCC. Pronounced swelling disappeared gradually, and it was already at a low level (6 quarters with moderate swelling) at PIH 72 . In the group receiving the low inoculum dose, changes in milk appearance and quarter swelling were equal to Group B, but the onset was about $3 \mathrm{~h}$ later. Teat relaxation, milk leakage, and diarrhea only appeared in a small number of animals in both infusion groups. The BCS decreased slightly from 3.5 to 2.5 from arrival at the dairy facility until the end of the intramammary $E$. coli challenge.

\section{Intramammary E. coli Challenge Induces Mainly Mild and Moderate Responses in Primiparous Cows Based on a Clinical Severity Scoring}

Based on the clinical severity scoring by Vangroenweghe et al. (2004), clinical changes appeared earlier in Group B compared with Group A. At PIH 9, 6 animals in Group B ( $\mathrm{n}=8)$ had a moderate clinical score; however, in Group A ( $\mathrm{n}=8)$, only 1 animal reacted moderately, whereas the others still exhibited a mild response $(P=0.041)$. By PIH 12 , only 4 animals in Group B ( $\mathrm{n}=8)$ reacted moderately, whereas in Group A $(\mathrm{n}=8), 6$ animals showed a moderate response $(P=$ 0.61 ) (Table 2). The clinical score normalized from PIH 15 onward, with only one animal in each group reacting moderately at PIH 15 and none at PIH 18. No severe responses were observed in either of the infusion groups at any time point between PIH 9 and 48 . 

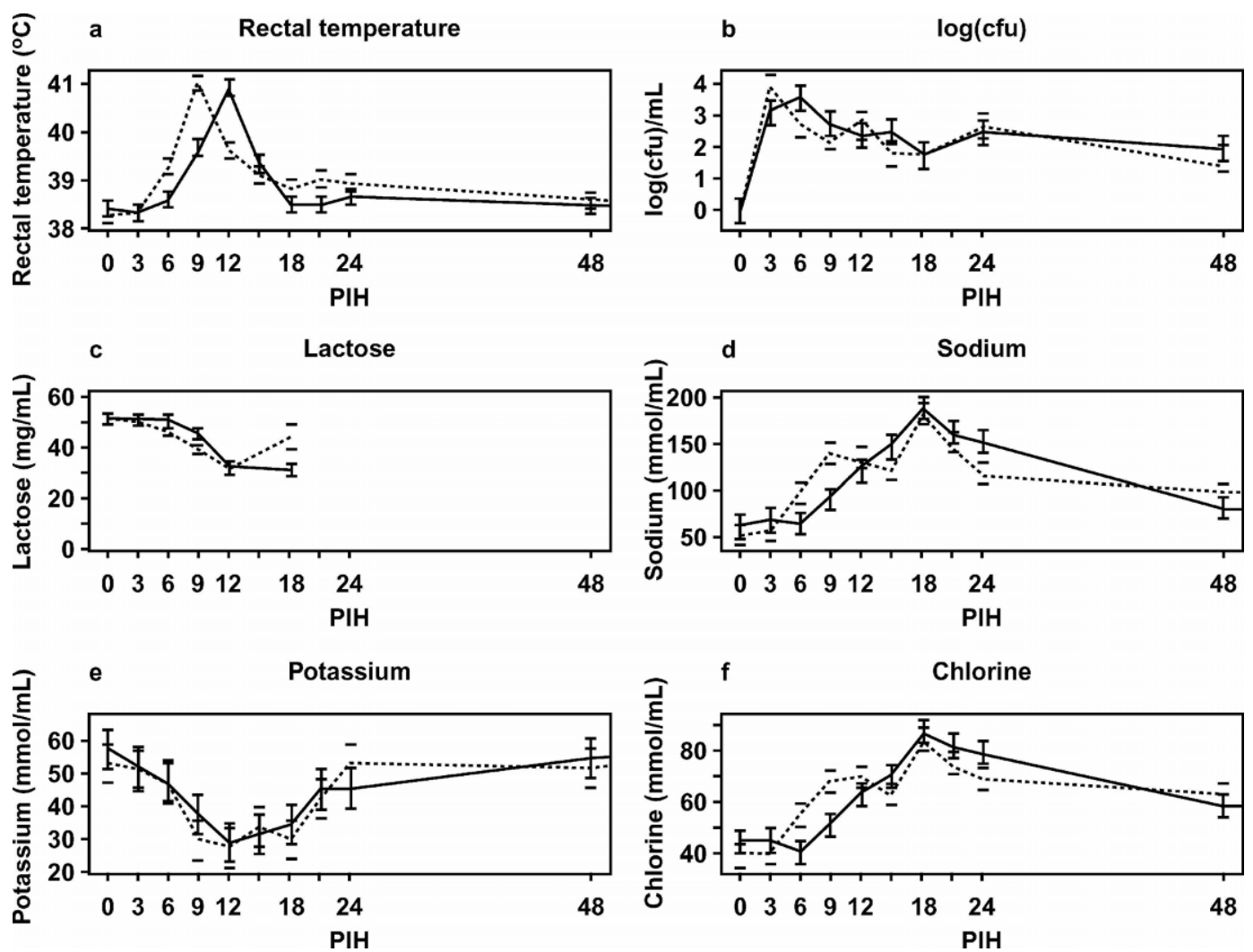

Figure 2. Rectal temperature (a), number of cfu Escherichia coli P4:O32 (b), lactose (c), milk sodium (d), milk potassium (e), and milk chlorine (f) from postinfusion hour (PIH) 0 until PIH 48 in the infected quarters, respectively, from primiparous cows infused with $1 \times 10^{4}$ (一; Group A; n = 8) and $1 \times 10^{6}(--$-; Group B; n = 8) cfu E. coli P4:O32. Data are means $( \pm \mathrm{SEM})$. PIH = postinfusion hour.

\section{Intramammary Growth of the Inoculated E. coli Resulted in a Pronounced Increase of SCC Through Recruitment of Circulating Blood Leukocytes}

The number of $E$. coli increased to peak values (3.96 and $3.20 \log _{10} \mathrm{cfu} / \mathrm{mL}$ ) at PIH 3 and 6 in the high and low dose infusion groups, respectively. On average, the number of $E$. coli did not significantly differ between the infusion groups. Furthermore, no significant interaction between time and inoculum dose were found, indicating that the number of $E$. coli changed over time in a similar fashion for the 2 inoculum doses (Figure 2b).

The SCC rapidly increased following intramammary $E$. coli infection and was significantly $(P<0.0001)$ higher at PIH 6 in the high dose infusion group compared with the group receiving the low dose. At PIH 9,

Table 2. Classification of heifers into mild, moderate, and severe responders based on the severity estimation score at postinfusion hour (PIH) 9 and 12. The numbers mentioned in the body of the table represent the number of animals with the specified score (sum of clinical parameters as specified in Table 1) at the respective PIH. In the present study, the total score did not exceed 5, meaning that no severe responses were observed throughout the entire experimental study period.

\begin{tabular}{|c|c|c|c|c|c|c|c|c|c|c|}
\hline \multirow[b]{3}{*}{ PIH } & \multirow[b]{3}{*}{ Group } & \multicolumn{9}{|c|}{ Clinical score } \\
\hline & & \multicolumn{3}{|c|}{ Mild response } & \multicolumn{3}{|c|}{ Moderate response } & \multicolumn{3}{|c|}{ Severe response } \\
\hline & & 0 & 1 & 2 & 3 & 4 & 5 & 6 & 7 & 8 \\
\hline \multirow[t]{2}{*}{9} & A & 2 & 2 & 2 & 2 & 0 & 0 & 0 & 0 & 0 \\
\hline & B & 0 & 0 & 1 & 5 & 2 & 1 & 0 & 0 & 0 \\
\hline \multirow[t]{2}{*}{12} & A & 0 & 1 & 1 & 5 & 1 & 0 & 0 & 0 & 0 \\
\hline & B & 0 & 2 & 2 & 3 & 1 & 0 & 0 & 0 & 0 \\
\hline
\end{tabular}



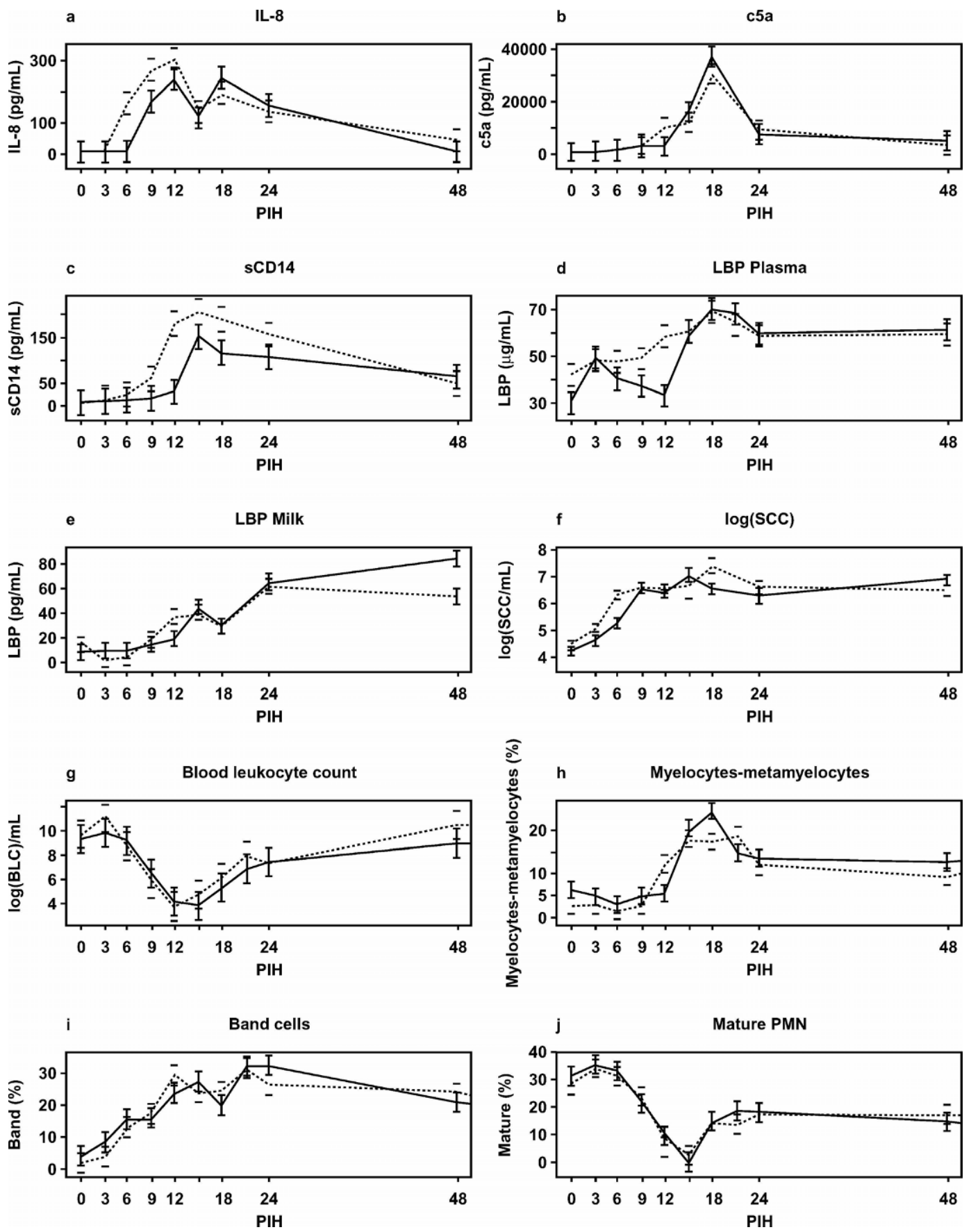

Figure 3. Interleukin-8 (a), complement fragment 5a (C5a) (b), soluble CD14 (sCD14) (c), plasma LPS-binding protein (LBP) (d), milk LBP (e), SCC (f), blood leukocyte count (g), percentage of myelocytes-metamyelocytes (h), percentage of band cells (i), and percentage of mature polymorphonuclear neutrophil (PMN) (j) from postinfusion hour (PIH) 0 until PIH 48 in the infected quarters or blood, respectively, from primiparous cows infused with $1 \times 10^{4}$ (一; Group A; n = 8) and $1 \times 10^{6}(--$-; Group B; n = 8) cfu Escherichia coli P4:O32. Data are means $( \pm$ SEM $) . P I H=$ postinfusion hour.

both infusion groups reached a plateau level of $10^{6.57}$ cells $/ \mathrm{mL}$ (Figure 3f). Peak SCC levels were reached at PIH 15 and 18 in Groups B and A, respectively. The SCC kinetics significantly differed $(P=0.0005)$ between the inoculum groups, especially because of the earlier cellular influx (PIH 6) in the infected quarters in Group B. At PIH 72, SCC did not yet attain preinfection SCC levels.

Although BLC decreased after intramammary E. coli infection, kinetics of the BLC decrease did not differ 
significantly between the inoculum groups. Nadir BLC was reached at PIH 12 in both infusion groups, and normal levels of circulating blood leukocytes appeared at PIH 48 (Figure 3g).

\section{Intramammary E. coli Challenge Induces the Appearance of Immature PMN into the Blood Circulation}

Following intramammary challenge, marked changes in differential BLC appeared, resulting in an increased number of early (myelocytes-metamyelocytes) and late (band cells) immature PMN in the blood circulation. Band cells increased from PIH 3 to peak at PIH 12 (Group B; $29.1 \pm 6.4 \%$ ) and PIH 15 (Group A; $27.2 \pm 2.4 \%$ ). A second peak was observed at PIH 21 $(32.3 \pm 2.8$ and $31.6 \pm 4.0 \%$ in Groups $A$ and $B$, respectively), after which the percentage of band cells decreased to normal levels by PIH 216 (Figure 3i). Early immature cells (myelocytes-metamyelocytes) appeared more frequently in the circulation from PIH 12 (Group B) and PIH 15 (Group A) onward, with peak values at PIH 18 (Group A; $24.1 \pm 2.5 \%$ ) and PIH 21 (Group B; $18.8 \pm 1.1 \%$ ). Myelocytes-metamyelocytes gradually decreased in the following $96 \mathrm{~h}$ to reach normal levels at PIH 144 to 216 (Figure 3h).

Mature PMN migrated from the circulation into the infected quarters, which resulted in a decreased percentage from PIH 9 onward in both groups, with nadir at PIH 15 (1.0 \pm 0.6 and $3.5 \pm 2.0 \%$ in Groups A and $\mathrm{B}$, respectively). The percentage of circulating mature PMN gradually recovered and reached preinfection values by PIH 144 (Figure 3j).

\section{Intramammary E. coli Challenge Induces Disruption of the Blood-Milk Barrier and Stimulates IL-8 and C5a Production in the Mammary Gland}

Lactose, sodium, potassium, and chloride are good indicators to assess the damage of the blood-milk barrier caused by the present IMI. Lactose decreased significantly in Group B from PIH 6 onward, to nadir at PIH 12 in both groups. In Group A, the disruption of the blood-milk barrier appears $3 \mathrm{~h}$ later, with a decrease in lactose content at PIH 9 (Figure 2c). Similarly, sodium and chloride concentrations in Group B increased from PIH 6 to peak a first time at PIH 9. Following a slight decrease at PIH 15, a second peak was reached at PIH 18. In Group A, infused with $1 \times 10^{4} \mathrm{cfu}$ per quarter, the onset of increased concentrations of sodium and chloride appeared at PIH 9, with maximal concentrations at PIH 18 (Figure 2, d and f). In contrast with the observed changes in sodium and chloride concentrations, potassium kinetics did not significantly differ be- tween both infusion groups. Nadir was reached at PIH 12 , followed by a slow restoration of initial potassium levels by PIH 48 (Figure 2e).

Before challenge, IL-8 was hardly detectable (2.19 \pm 0.93 and $1.89 \pm 0.84 \mathrm{pg} / \mathrm{mL}$ in Groups A and B, respectively) in the quarters that were to be infused with $E$. coli. The IL-8 kinetics of the 2 infusion groups differed significantly from each other. In Group B, a significant increase in IL-8 appeared as early as PIH 6 and reached a peak of $305 \pm 36 \mathrm{pg} / \mathrm{mL}$ at PIH 12 (Figure 3a). At PIH 6 and 9, the concentration of IL-8 in the inflamed quarters was significantly higher $(P<0.05)$ in Group B, which received the $1 \times 10^{6} \mathrm{cfu}$ inoculum dose. Following infusion of $1 \times 10^{4} \mathrm{cfu}$ (Group A), significant increases in IL-8 occurred at PIH 9 and reached peak levels of $240 \pm 40 \mathrm{pg} / \mathrm{mL}$ at PIH 12. Elevated levels of IL-8 persisted until PIH 24 in both groups, after which the levels returned to baseline.

The complement component C5a had similar kinetics in both groups. The initial increase in C5a following intramammary challenge appeared at PIH $6( \pm 1.5 \mathrm{ng} /$ $\mathrm{mL}$ ), and it rapidly increased to $37.1 \pm 16.0 \mathrm{ng} / \mathrm{mL}$ and $30.6 \pm 12.4 \mathrm{ng} / \mathrm{mL}$ at PIH 12 for Groups A and B, respectively. Elevated levels of C5a persisted until PIH 24 in both groups, after which the levels returned to baseline (Figure 3b).

\section{Intramammary E. coli Challenge Increases Milk sCD14 Levels}

To determine whether $E$. coli could alter mammary gland levels of sCD14, a sandwich ELISA was used to quantitate milk sCD14 (Figure 3c). Before challenge, sCD14 in mammary quarters $(7.7 \pm 2.7$ and $10.4 \pm 3.1$ $\mu \mathrm{g} / \mathrm{mL}$ for Groups A and B, respectively) was in the range previously described (Lee et al., 2003a) for early lactating noninfected glands (5.46 to $6.90 \mu \mathrm{g} / \mathrm{mL}$ ). At $\mathrm{PIH} 6$, a significant increase in milk sCD14 was observed in Group B, whereas in Group A, the increase in milk sCD14 only appeared at PIH 9. Concentrations of sCD14 were significantly $(P<0.0001)$ different between the 2 groups at PIH 12. Milk sCD14 peaked at $\mathrm{PIH} 15$ in both groups, although the level of sCD14 was significantly higher $(P=0.0323)(205 \pm 44 \mu \mathrm{g} / \mathrm{mL})$ in Group B compared with Group A (151 $\pm 54 \mu \mathrm{g} / \mathrm{mL})$ (Figure 3c).

\section{Increased Levels of LBP in Milk Following Intramammary Challenge with $E$. coli}

It has been shown previously (Bannerman et al., 2003) that elevated levels of SCD14 are associated with similar increases in milk LBP, thereby providing an environment for optimal host recognition of LPS, origi- 
nating from infused $E$. coli bacteria. Plasma LBP was also assayed, as it is known that hepatic synthesis of this protein increases during the acute phase response, mainly because of hepatic cell stimulation by IL- $1 \beta$ and IL-6 (Tobias et al., 1999). Under basal conditions, LBP was detected in bovine blood at concentrations of 29.8 \pm 7.5 and $41.9 \pm 5.4 \mu \mathrm{g} / \mathrm{mL}$ for Groups $\mathrm{A}$ and $\mathrm{B}$, respectively; whereas the concentration of LBP in milk was lower with $8.5 \pm 5.1$ and $14.5 \pm 11.5 \mu \mathrm{g} / \mathrm{mL}$ for Groups A and B, respectively. At PIH 9, plasma LBP in Group $B$ increased, and this increase persisted throughout the entire study period (Figure 3d). Plasma LBP levels reached maximal levels of $70.1 \pm 1.5$ and $68.8 \pm 1.1 \mu \mathrm{g} /$ $\mathrm{mL}$ at PIH 18, after which they slightly declined to reach a plateau until the end of the study. In quarters inoculated with $E$. coli, significant elevation of milk LBP was observed as early as PIH 9, resulting in a first peak at PIH $15(44.4 \pm 10.6$ and $40.4 \pm 8.7 \mu \mathrm{g} / \mathrm{mL}$ in Groups A and B, respectively). Milk LPB was significantly $(P=0.0431)$ higher in Group B at PIH 12 . A second peak $(61.6 \pm 12.3$ and $61.2 \pm 12.0 \mu \mathrm{g} / \mathrm{mL}$ in Groups A and B, respectively) was reached at PIH 24, after which milk LBP levels remained high until the end of the study (Figure 3e). Peak levels of milk LBP were observed $6 \mathrm{~h}$ later than the maximal elevation of plasma LBP levels.

\section{DISCUSSION}

In this study, the same strain and range of high inoculum doses of $E$. coli was used to induce $E$. coli mastitis as reported in previous studies (Heyneman et al., 1990; Vandeputte-Van Messom et al., 1993; Hoeben et al., 2000; Dosogne et al., 2002; Vangroenweghe et al., 2004). The outcome of experimental $E$. coli inoculation was expected based on the results obtained in a previous study with primiparous cows under identical conditions (Vangroenweghe et al., 2004). In the present study, none of the animals reacted severely following intramammary E. coli challenge. Animals were scored as described by Vangroenweghe et al. (2004), which resulted in a similar classification of mild and moderate responses. Interestingly, the time of latency to become moderately ill was approximately $3 \mathrm{~h}$ shorter in Group B compared with Group A.

The number of circulating PMN, a marker to predict the clinical outcome of the disease, was similar to the levels previously observed in moderate responders (Vandeputte-Van Messom et al., 1993; Vangroenweghe et al., 2004). Primiparous cows in this study could, therefore, be expected to react with a moderate clinical response. Following intramammary $E$. coli challenge, a rapid decrease of circulating PMN was observed, which coincided with the influx of PMN into the infected quar- ters and started around PIH 6 to 9. Remarkably, no significant difference in BLC kinetics could be observed between the infusion groups, whereas, for SCC, a significantly earlier influx was observed in the high dose inoculum group.

The onset of local clinical signs of mastitis, characterized by quarter swelling, coincided with the influx of PMN to the infected quarters. The SCC increased rapidly in both groups, which is in accordance with earlier observations, where moderate responders had a rapidly occurring leukocytosis in the infected glands (Vandeputte-Van Messom et al., 1993). However, in the present study, distinct differences in the onset of PMN influx into the infected glands could be observed. The extraction of mature PMN from the blood to the infected glands is known to result in early and late immature PMN recruitment from the bone marrow to restore the number of circulating PMN. Recently, IL-8 has been shown to be responsible for rapid granulocytosis with the release of PMN from the bone marrow (Terashima et al., 1998). In the present study, IL-8 was released from PIH 6 to 9, which coincided with the appearance of significantly increased numbers of band cells in the blood circulation. However, the recruitment of PMN was of short duration, compared with Heyneman et al. (1990), who observed immature forms in circulation for at least $3 \mathrm{~d}$ in moderate responders and for almost 10 $\mathrm{d}$ in severe responders.

The rapid influx of PMN into the infected glands was associated with rapid elimination of bacteria from the quarters. In contrast to an earlier study with the same inoculum dose in multiparous animals (VandeputteVan Messom et al., 1993), peak bacterial numbers were already reached around PIH 3 to 6, which was in accordance with a previous study in primiparous cows (Vangroenweghe et al., 2004). Contrary to the induction of $E$. coli mastitis with low inoculum doses, where elimination is preceeded by excessive bacterial growth (Shuster et al., 1996, 1997; Riollet et al., 2000; Scaletti et al., 2003), in this study, peak numbers were reached within $6 \mathrm{~h}$ postinfusion and followed by a subsequent bacterial elimination.

Several indicators (lactose, sodium, chloride, and potassium) for the disintegration of the blood-milk barrier were determined in this study. The changes appeared significantly earlier (approximately $3 \mathrm{~h}$ ) in Group B, receiving the $1 \times 10^{6}$-cfu inoculum dose, although peak levels were almost identical for both groups, which coincides with all other data, indicating that the animals reacted with a mild to moderate response and little variation in clinical response was present in this study.

Complement component $\mathrm{C} 5 \mathrm{a}$ and its derivative $\mathrm{C} 5 \mathrm{a}^{\text {desArg }}$ play a potential role in the inflammatory response accompanying mastitis (Rainard et al., 1998). 
The level of $\mathrm{C} 5 \mathrm{a} / \mathrm{C} 5 \mathrm{a}^{\text {desArg }}$ on the day of challenge was within the range previously described by Rainard et al. (1998), taking into account that the average SCC immediately before intramammary infusion was a little higher (approximately 90,000 vs. 25,000 cells $/ \mathrm{mL}$ ). In the present study, increased levels of $\mathrm{C} 5 \mathrm{a} / \mathrm{C} 5 \mathrm{a}^{\mathrm{des} A r g}$ could be observed from PIH 3 onward, which is in accordance with an earlier study (Rainard et al., 1998), although in that study the induction of inflammatory symptoms was performed with $E$. coli endotoxin and not with live bacteria. The assessment of C5 $\mathrm{a}^{\text {desArg }}$ concentrations in milk following infusion of $E$. coli endotoxin or live bacteria showed that biologically significant amounts of $\mathrm{C} 5 \mathrm{a} / \mathrm{C} 5 \mathrm{a}^{\text {desArg }}$ are present in mastitic milk. The bulk of complement-derived components in mastitic milk are likely to have their origin in blood plasma, exudating through the damaged blood-milk barrier following inflammation of the mammary gland (Rainard et al., 1998). However, milk concentrations of $\mathrm{C} 5 \mathrm{a} / \mathrm{C} 5 \mathrm{a}^{\mathrm{des} A r g}$ are probably not a reliable indicator of exudation, as $\mathrm{C} 5 \mathrm{a} / \mathrm{C} 5 \mathrm{a}^{\text {desArg }}$ is rapidly taken up by several cell types present in inflamed milk, in particular PMN (Rainard et al., 1998). Major clearance mechanism of this inflammatory mediator is believed to rely on the binding of C5a/C5a ${ }^{\text {desArg }}$ to cell surface receptors. As milk from inflamed quarters contained high concentrations of cells, mainly PMN, it can be put forward that the concentrations of $\mathrm{C} 5 \mathrm{a} / \mathrm{C} 5 \mathrm{a}^{\mathrm{des} A r g}$ measured in milk were underestimates of the total amounts of C5a/ C5 $\mathrm{a}^{\text {desArg }}$ originally generated. Complement fragment 5 a generated in milk could well contribute to the activation of the recruited phagocytic cells, with the consequence of improving their bactericidal activity (Rainard, 2003).

Interleukin-8 is considered to play an important role in PMN recruitment to the inflamed quarters (Baggniolini and Clark-Lewis, 1992; Barber and Yang, 1998). In contrast to Shuster et al. (1997), who suggested the importance of C5a is greater than IL-8 during the early inflammatory response mainly because of earlier peak maxima, in the present study, peak levels of IL-8 appeared $6 \mathrm{~h}$ earlier than C5a. The increase of IL-8 chemotactic activity appears coincident with the increment in SCC at the level of the infected quarters. An increase in C5a also appeared as early as PIH 3 to 6 , but its peak maximum was only reached at PIH 18 . The induction of IL-8 production and release is known to be independent of the presence of IL- $1 \beta$ and TNF- $\alpha$ (Persson-Waller et al., 2003).

Detectable increases in milk LBP were observed after initial increases in blood LBP, and maximal levels of LBP in milk were observed at PIH 24, some $6 \mathrm{~h}$ after the peak levels of plasma LBP. In accordance with Bannerman et al. (2003), the increases in milk LBP paralleled increments in sCD14 levels. From a host perspective, the simultaneous increase in both LBP and sCD14 levels would be expected to be advantageous as both molecules act in concert to facilitate activation of host defense mechanisms by presenting LPS, released during bacterial growth and death, to the transmembrane LPS receptor, TLR-4 (Bannerman and Goldblum, 2003). Although the increase in sCD14 was earlier and significantly higher in Group B, PMN influx as determined by SCC in the infected quarters was similarly elevated before pronounced increment of sCD14. It was proposed that heightened levels of these molecules are not required for immediate host innate immune responses (Bannerman et al., 2003). However, peak levels of SCC were not observed until PIH 15 to 18 , at a time where levels of both sCD14 and LBP in milk were elevated. Whether increments in sCD14 and LBP are necessary for maximal recruitment of PMN to the inflamed mammary glands remains unknown.

From this study, it appears that the inflammatory response in primiparous cows from Group B has an earlier onset compared with Group A. One possible explanation for this observation could be the 100 -fold difference in the number of $E$. coli infused into the mammary glands because the amount of LPS produced is related to the number of $E$. coli bacteria (Burvenich, 1983; Monfardini et al., 1999). Because the bacterial cultures were washed $3 \times$ in pyrogen-free PBS before further dilutions were made, a direct effect of LPS present in the inoculum can be excluded. Known as a potent inducer of inflammatory cytokines (Shuster et al., 1993), LPS can be produced quite rapidly during bacterial growth following intramammary infusion. The infused bacteria rapidly activated the complement system through the alternative pathway, resulting in an early abundant production of $\mathrm{C} 5 \mathrm{a}$. These effects resulted in a rapid attraction of PMN from the blood into the mammary gland, with a subsequent pronounced increase of SCC in the infected glands.

The novelty of the present study is the fact that primiparous cows, recently shown to react as mild to moderate responders (Vangroenweghe et al., 2004), are responding faster following a 100 -fold increase in the inoculum dose. This quicker response is related to an earlier activation of innate host immunity.

Following $E$. coli mastitis, treatment with antibiotics at PIH 10 did not alter local and systemic symptoms despite a 100-fold decrease in colony-forming units (Monfardini et al., 1999). From the present study, it is evident that at the set time point, antibiotic treatment is unable to alter the production or release of various inflammatory mediators. Therefore, it can be suggested that early inflammatory events (first $3 \mathrm{~h}$ ) could play a 
major role in the further regulation of the inflammatory response to combat the invading pathogens.

\section{CONCLUSIONS}

Despite the use of relatively high inoculum doses, primiparous cows react with a moderate inflammatory response following intramammary $E$. coli infusion. This moderate response was evident from the preinfection number of circulating leukocytes, the prompt clinical response, the rapid influx of PMN into the infected quarters, the efficient bacterial clearance of the affected glands, and the fast recovery of QMP in both infected and noninfected glands. In the present study, the difference in time of latency between both inoculum doses could be confirmed and documented with kinetics of various inflammatory mediators, such as SCD14, LBP, IL-8, and C5a. The early increase in IL-8 following activation of the mammary gland epithelium appeared before increases in $\mathrm{SCD} 14$ or LBP, indicating that innate host cell activation can occur in the presence of basal levels of sCD14 and LBP. Although C5a increased during early innate host immune response, maximal levels were reached after IL-8 had peaked. In conclusion, heifers were able to efficiently clear an intramammary $E$. coli infection, and the increase in inoculum dose induced a more rapid clinical response, mainly because of the earlier activation of the innate host immune response. To further elucidate the regulation of early events, mammary gland biopsies and milk sample collection during the early phase of inflammation should be performed.

\section{ACKNOWLEDGMENTS}

This study was supported by the Fund for Scientific Research-Flanders (FWO-Vlaanderen, grant no. 31520804). The first author participated in a ShortTerm Scientific Mission, STSM of COST B20 (student exchange network of COST B20, Mammary Gland Biology Group, of the EU). The authors greatly appreciated the excellent technical assistance of E. Vander Elstraeten, A. Vervloet, E. Van Driessche, J. Van Groenweghe, G. Corneillie, K. Demeyere, and J.-P. Fontaine.

\section{REFERENCES}

Aderem, A., and R. J. Ulevitch. 2000. Toll-like receptors in the induction of the innate immune response. Nature (Lond.) 460:782-787.

Akashi, S., H. Ogata, F. Kirikae, T. Kirikae, K. Kawasaki, M. Nishijima, R. Shimazu, Y. Nagai, K. Fukudome, M. Kimoto, and K. Miyake. 2000. Regulatory roles for CD14 and phosphatidylinositol in the signalling via Toll-like receptor 4-MD-2. Biochem. Biophys. Res. Commun. 268:172-177.

Baggniolini, M., and I. Clark-Lewis. 1992. Interleukin-8, a chemotactic and inflammatory cytokine. FEBS Lett. 307:97-101.
Bannerman, D. D., and S. E. Goldblum. 2003. Mechanisms of bacterial lipopolysaccharide-induced endothelial apoptosis. Am. J. Physiol. Lung Cell. Mol. Physiol. 284:L899-L914.

Bannerman, D. D., M. J. Paape, W. R. Hare, and E. J. Sohn. 2003. Increased levels of LPS-binding protein in bovine blood and milk following bacterial lipopolysaccharide challenge. J. Dairy Sci. 86:3128-3137.

Barber, M. R., and T. J. Yang. 1998. Chemotactic activities in nonmastitic and mastitic mammary secretions: Presence of interleukin8 in mastitis but not in nonmastitic secretions. Clin. Diagn. Lab. Immunol. 5:82-86.

Bramley, A. J. 1976. Variations in the susceptibility of lactating and non-lactating bovine udders to infection when infused with Escherichia coli. J. Dairy Res. 43:205-211.

Burvenich, C. 1983. Mammary blood flow in conscious lactating goats in various physiological and pathological (mastitis) conditions. Ph.D. Diss., Faculty of Veterinary Medicine, Ghent Univ., Ghent, The Netherlands.

Burvenich, C., V. Van Merris, J. Mehrzad, A. Diez-Fraile, and L. Duchateau. 2003. Severity of E. coli mastitis is mainly determined by cow factors. Vet. Res. 34:521-564.

Chow, J. C., D. W. Young, D. T. Golenbock, W. J. Christ, and F. Gusovsky. 1999. Toll-like receptor-4 mediates lipopolysaccharideinduced signal transduction. J. Biol. Chem. 274:10689-10692.

Detilleux, J. C., M. E. Kehrli, Jr., J. R. Stabel, A. E. Freeman, and D. H. Kelley. 1995. Study of immunological dysfunction in periparturient Holstein cattle selected for high and average milk production. Vet. Immunol. Immunopathol. 44:251-267.

Dosogne, H., C. Burvenich, A. E. Freeman, M. E. Kehrli, Jr., J. C. Detilleux, J. Sulon, J.-F. Beckers, and D. Hoeben. 1999. Association between pregnancy-associated glycoprotein and decreased polymorphonuclear leukocyte function in early postpartum dairy cows. Vet. Immunol. Immunopathol. 67:47-54.

Dosogne, H., C. Burvenich, T. van Werven, E. Roets, E. N. Noordhuizen-Stassen, and B. Goddeeris. 1997. Increased surface expression of $\mathrm{CD} 11 \mathrm{~b}$ receptors on polymorphonuclear leukocytes is not sufficient to sustain phagocytosis during Escherichia coli mastitis in early postpartum dairy cows. Vet. Immunol. Immunopathol. 60:47-59.

Dosogne, H., E. Meyer, A. Sturk, J. van Loon, A.-M. Massart-Leën, and C. Burvenich. 2002. Effect of enrofloxacin treatment on plasma endotoxin during bovine Escherichia coli mastitis. Inflamm. Res. 51:201-205.

Edmondson, A. J., I. J. Lean, I. D. Weaver, T. Farver, and G. Webster. 1989. A body condition scoring chart for Holstein dairy cows. J. Dairy Sci. 72:68-78.

Faure, E., J. W. Equils, P. A. Sieling, L. Thomas, F. X. Zhang, C. J. Krischning, N. Polentarutti, M. Muzio, and M. Arditi. 2000. Bacterial lipopolysaccharide activates NF- $\kappa$ B through Toll-like receptor 4 (TLR-4) in cultured human dermal endothelial cells. Differential expression of TLR-4 and TLR-2 in endothelial cells. J. Biol. Chem. 275:11058-11063.

Gilbert, R. O., Y. T. Gröhn, P. M. Miller, and D. J. Hoffman. 1993. Effect of parity on periparturient neutrophil function in dairy cows. Vet. Immunol. Immunopathol. 36:75-82.

Guha, M., and N. Mackman. 2001. LPS induction of gene expression in human monocytes. Cell. Signal. 13:85-94.

Heyneman, R., C. Burvenich, and R. Vercauteren. 1990. Interaction between the respiratory burst activity of neutrophil leukocytes and experimentally induced Escherichia coli mastitis in cows. J. Dairy Sci. 73:985-994.

Hill, A. W. 1981. Factors influencing the outcome of Escherichia coli mastitis in the dairy cow. Res. Vet. Sci. 73:985-994.

Hoeben, D., C. Burvenich, E. Trevisi, G. Bertoni, J. Hamann, R. M. Bruckmaier, and J. W. Blum. 2000. Role of endotoxin and TNF$\alpha$ in the pathogenesis of experimentally induced coliform mastitis in periparturient cows. J. Dairy Res. 67:503-514.

Kehrli, M. E., Jr., and J. P. Goff. 1989. Periparturient hypocalcemia in cows: Effects on peripheral blood neutrophil and lymphocyte function. J. Dairy Sci. 72:1188-1196. 
Kehrli, M. E., Jr., B. J. Nonnecke, and J. A. Roth. 1989. Alterations in bovine neutrophil function during the periparturient period. Am. J. Vet. Res. 50:207-214.

Kimura, K., J. P. Goff, and M. E. Kehrli, Jr. 1999. Effects of the presence of the mammary gland on expression of neutrophil adhesion molecules and myeloperoxidase activity in periparturient dairy cows. J. Dairy Sci. 82:2385-2392.

Kimura, K., J. P. Goff, M. E. Kehrli, Jr., and T. A. Reinhardt. 2002. Decreased neutrophil function as a cause of retained placenta in dairy cattle. J. Dairy Sci. 85:544-550.

Lee, J.-W., M. J. Paape, T. H. Elsasser, and X. Zhao. 2003a. Elevated milk soluble CD14 in bovine mammary glands challenged with Escherichia coli lipopolysaccharide. J. Dairy Sci. 86:2382-2389.

Lee, J.-W., M. J. Paape, T. H. Elsasser, and X. Zhao. 2003b. Recombinant soluble CD14 reduces severity of intramammary infection by Escherichia coli. Infect. Immun. 71:4034-4039.

Lee, J.-W., M. J. Paape, and X. Zhao. 2003c. Recombinant bovine soluble CD14 reduces severity of experimental Escherichia coli mastitis in mice. Vet. Res. 34:307-316.

Massart-Leën, A.-M., G. Vandeputte-Van Messom, and C. Burvenich. 1988. Oxytocin release during experimentally induced fever and inflammation in lactating ruminants. Arch. Int. Physiol. Biochim. 96:43-44.

Mehrzad, J., H. Dosogne, E. Meyer, R. Heyneman, and C. Burvenich. 2001. Respiratory burst activity of blood and milk neutrophils in dairy cows during different stages of lactation. J. Dairy Res. 68:399-415.

Mehrzad, J., L. Duchateau, S. Pyörälä, and C. Burvenich. 2002. Blood and milk neutrophil chemiluminescence and viability in primiparous and pluriparous dairy cows during late pregnancy around parturition and early lactation. J. Dairy Sci. 85:3268-3276.

Monfardini, E., C. Burvenich, A.-M. Massart-Leën, E. Smits, and M. J. Paape. 1999. Effect of antibiotic induced bacterial clearance in the udder on L-selectin shedding of blood neutrophils in cows with Escherichia coli mastitis. Vet. Immunol. Immunopathol. 67:373-384.

Persson-Waller, K., I. G. Colditz, S. Lun, and K. Östensson. 2003. Cytokines in mammary lymph and milk during endotoxin-induced bovine mastitis. Res. Vet. Sci. 74:31-36.

Rainard, P. 2003. The complement in milk and defense of the bovine mammary gland against infection. Vet. Res. 34:647-670.

Rainard, P., P. Sarradin, M. J. Paape, and B. Poutrel. 1998. Quantification of $\mathrm{C} 5 \mathrm{a} / \mathrm{C} 5 \mathrm{a}^{\text {desArg }}$ in bovine plasma, serum and milk. Vet. Res. 29:73-88.

Riollet, C., P. Rainard, and B. Poutrel. 2000. Differential induction of complement fragment C5a and inflammatory cytokines during intramammary infections with Escherichia coli and Staphylococcus aureus. Clin. Diagn. Lab. Immunol. 7:161-167.

Scaletti, R. W., D. S. Trammell, B. A. Smith, and R. J. Harmon. 2003. Role of dietary copper in enhancing resistance to Escherichia coli mastitis. J. Dairy Sci. 86:1240-1249.

Shuster, D. E., M. E. Kehrli, Jr., P. Rainard, and M. Paape. 1997. Complement fragment C5a and inflammatory cytokines in neu- trophil recruitment during intramammary infection with Escherichia coli. Infect. Immun. 65:3286-3292.

Shuster, D. E., M. E. Kehrli, Jr., and M. G. Stevens. 1993. Cytokine production during endotoxin-induced mastitis in lactating dairy cows. Am. J. Vet. Res. 54:80-85.

Shuster, D. E., E. K. Lee, and M. E. Kehrli, Jr. 1996. Bacterial growth, inflammatory cytokine production, and neutrophil recruitment during coliform mastitis in cows within ten days after calving, compared with cows at midlactation. Am. J. Vet. Res. 57:15691575.

Sordillo, L. M., and L. A. Babiuk. 1991a. Controlling acute Escherichia coli mastitis during the periparturient period with recombinant bovine interferon gamma. Vet. Microbiol. 28:189-198.

Sordillo, L. M., and L. A. Babiuk. 1991b. Modulation of bovine mammary neutrophil function during the periparturient period following in vitro exposure to recombinant bovine interferon gamma. Vet. Immunol. Immunopathol. 27:393-402.

Sordillo, L. M., and J. E. Peel. 1992. Effect of interferon-g on the production of tumor necrosis factor during acute Escherichia coli mastitis. J. Dairy Sci. 75:2119-2125.

Tapping, R. L., and P. S. Tobias. 1997. Cellular binding of soluble CD14 requires lipopolysaccharide (LPS) and LPS-binding protein. J. Biol. Chem. 272:23157-23164.

Terashima, T., D. English, J. C. Hogg, and S. F. van Eeden. 1998. Release of polymorphonuclear leukocytes from the bone marrow by interleukin-8. Blood 92:1062-1069.

Thomas, C. J., M. Kapoor, S. Sharma, H. Bausinger, U. Zyilan, D. Lipsker, D. Hanau, and A. Surolia. 2002. Evidence of a trimolecular complex involving LPS, LPS binding protein and soluble CD14 as an effector of LPS response. FEBS Lett. 531:184-188.

Tobias, P. S., R. L. Tapping, and J. A. Gegner. 1999. Endotoxin interactions with lipopolysaccharide-responsive cells. Clin. Infect. Dis. 28:476-481.

Vandeputte-Van Messom, G., C. Burvenich, E. Roets, A.-M. MassartLeën, R. Heyneman, W. D. J. Kremer, and A. Brand. 1993. Classification of newly calved cows into moderate and severe responders to experimentally induced Escherichia coli mastitis. J. Dairy Sci. 60:19-29.

Vangroenweghe, F., L. Duchateau, and C. Burvenich. 2004. Moderate inflammatory response during experimental $E$. coli mastitis in primiparous cows. J. Dairy Sci. 87:886-895.

van Werven, T., E. N. Noordhuizen-Stassen, A. J. J. M. Daemen, Y. H. Schukken, A. Brand, and C. Burvenich. 1997. Preinfection in vitro chemotaxis, phagocytosis, oxidative burst, and expression of CD11/CD18 receptors and their predictive capacity on the outcome of mastitis induced in dairy cows with Escherichia coli. J. Dairy Sci. 80:67-74.

Wang, Y., D. S. Zarlenga, M. J. Paape, and G. E. Dahl. 2002. Recombinant bovine soluble CD14 sensitizes the mammary gland to lipopolysaccharide. Vet. Immunol. Immunopathol. 86:115-124.

Wilde, J. K. H. 1964. The cellular elements of the bovine bone marrow. Res. Vet. Sci. 5:213-227.

Wright, S. D., R. A. Ramos, P. S. Tobias, R. J. Ulevitch, and J. C. Mathison. 1990. CD14, a receptor for complexes of lipopolysaccharide (LPS) and LPS binding protein. Science 249:1431-1433. 